\title{
A concise assessment of salivary modifications in patients with chronic hepatitis
}

\author{
Daniela-Gabriela BADITA ${ }^{1}$, Dan PIPEREA-SIANU ${ }^{1}$, Andra-Elena BALCANGIU-STROESCU ${ }^{1}$, \\ Bogdan CALENIC ${ }^{1}$, Maria GREABU ${ }^{1}$, Maria-Daniela TANASESCU ${ }^{1,2}$, Laura RADUCU ${ }^{3}$, \\ Iulia-Ioana STANESCU ${ }^{1}$ \\ 1"Carol Davila" University of Medicine and Pharmacy, Bucharest, Romania \\ ${ }^{2}$ Department of Nephrology, Emergency University Hospital, Bucharest, Romania \\ ${ }^{3}$ Discipline of Plastic Surgery and Plastic Reconstructive Microsurgery, "Prof. Dr. Agrippa Ionescu" \\ Emergency Clinical Hospital, Bucharest, Romania
}

\begin{abstract}
- ABSTRACT
Background. Saliva is a complex biological fluid that has great potential as a diagnosis fluid for both oral and systemic diseases. At the same time, chronic hepatitis affects millions of people worldwide and can lead to liver cirrhosis and hepatocellular carcinoma. In this context, our research group aimed to evaluate the modifications produced in the saliva of patients with chronic hepatitis compared to healthy subjects.

Material and method. The present work included 88 subjects that were divided into 4 groups, each consisting of 22 people. Saliva samples were collected for each participant to the study. Salivary levels of total protein (TP), IgA, IgG and aminotransferases AST (aspartate aminotransferase) and ALT (alanine aminotransferase) were determined.

Results. Our results showed significantly increased salivary levels of TP, IgA, AST and ALT for patients with chronic viral hepatitis (CHV) and chronic alcoholic hepatitis (CAH) compared to controls. IgG salivary levels were also higher in patients with hepatitis versus controls, however while statistical significance could be found for patients with chronic hepatitis $\mathrm{C}(\mathrm{CHC})$ and $\mathrm{CAH}$, this was not the case for the patients with chronic hepatitis $B(\mathrm{CHB})$.

Conclusions. The results of our study showed significantly increased salivary levels of the determined parameters in hepatitis patients compared to the healthy subjects, hence promoting the use of saliva as a diagnosis and monitoring fluid for chronic hepatitis.
\end{abstract}

Keywords: chronic viral hepatitis, chronic alcoholic hepatitis, saliva

\section{INTRODUCTION}

During the last decades, saliva has shown its potential as a viable alternative to serum and plasma as a diagnosis and monitoring fluid for systemic diseases. The correlations between serum and salivary levels of the biomarkers promote the use of this easily collected and non-invasive fluid. Moreover, salivary analysis doesn't require big samples or specialized equipment, thus providing multiple advantages (1).

Chronic liver disease includes the inflammatory processes in viral hepatitis as well as more severe cases consisting of liver cirrhosis and hepatocellular carcinoma. It involves progressive destruction and regeneration of the hepatic parenchymal tissue that last for at least 6 
months and evolve towards liver fibrosis and hepatic cirrhosis. Over 240 million people worldwide have been diagnosed with chronic hepatitis and every year approximately 600.000 people die because of acute or chronic viral hepatitis $B(\mathrm{VHB})$ or C (VHC) (2).

Apart from viral infection, multiple factors have been incriminated in the development of chronic hepatitis, including medicines and drugs, with genetics and autoimmunity also playing an important role $(2,3)$. At the same time, it has been proven that chronic alcohol consumption leads to major liver impairment, causing steatosis, fibrosis and eventually conducting to liver cirrhosis. Chronic viral hepatitis has a variable clinical presentation, ranging from asymptomatic cases to fatigue, weight loss, anorexia or hepatosplenomegaly. Cutaneous manifestations, diarrhea or arthritis can appear in cases of active chronic viral hepatitis $(4,5)$.

In this context, the main objective of our study was to analyze the alterations produced in salivary composition in patients with chronic hepatitis. Thus, our research group aimed to assess the possibility of using saliva as a diagnosis fluid for hepatitis and as a tool in the differential diagnosis between viral and alcoholic hepatitis.

\section{MATERIAL AND METHOD}

\section{Patient selection}

Our study included 88 participants, 57 men and 31 women, divided into 4 groups, each group consisting of 22 subjects. Group 1 (the control group) was represented by clinically and biologically healthy subjects with no prior history of hepatitis, 13 men and 9 women. Group 2 (CHB) was formed by 14 men and 8 women with chronic viral hepatitis $B(\mathrm{VHB})$, group $3(\mathrm{CHC})$ was represented by 11 men and 11 women with chronic viral hepatitis $\mathrm{C}(\mathrm{VHC})$, while group 4 (CAH) included 19 men and 3 men with chronic hepatitis of alcoholic etiology.

Clinical parameters such as age, sex, geographical area, weight and height, as well as information regarding smoking habits and alcohol consumption were noted for all the subjects included.

\section{Patient diagnosis}

Clinical and laboratory data were used to assess the hepatitis diagnosis and in some of the cases a liver histopathological examination was necessary. We determined serum anti-VHA IgM,
anti-HBc IgM, AgHbs, AgHBe, anti-Hbe, anti-HBc, Ag-VHD, anti-VHD, anti-VHC, ARN-VHC for all subjects.

The patients with chronic hepatitis with alcoholic etiology included in the fourth group presented a case history of chronic alcohol consumption, negative viral markers, clinical symptomatology and a paraclinical presentation sugestive for liver impairment.

\section{Saliva collection}

Saliva samples were collected between 8.30 and 9.30 in the morning. Each participant to the present research was asked not to eat for at least 12 before sampling. Subjects were required to provide information regarding any medical treatment curently administered and medication other than compulsatory was prohibited in the last 24 hours prior to the collection. In most cases, the medication was administered after the sampling. Dental brushing was allowed to be performed with at least 120 minutes previously to the samples collection, taking into consideration that minor lessions that can appear during brushing can produce exsudate and thus, modifying salivary composition. Flossing as well as other auxilliar methods of dental hygiene were prohibited after brushing. Smoking and physical effort were also not allowed in the morning that the sampling was performed. 15 minutes before collection the participants to the study were asked to rinse their mouth with distilled water and afterwards liquid consumption was forbidden.

Total unstimulated saliva was collected for 10 minutes in sterile, graded tubes that were held on ice. During the sampling the subjects were asked to refrain from talking or swallowing. Saliva samples were centrifuged for $20 \mathrm{~min}-$ utes at 6.000 rotations/minute.

Total protein (TP), immunoglobulins G (IgG) and A (IgA), as well as aminotransferases AST and ALT were determined for each subject included in our research.

\section{Statistical analysis}

Results were expressed as mean \pm standard deviation (SD). Student T-test was used to perform statistical differences between the groups. A $p$-value $<0.05$ was considered statistically significant. In order to analize the possible correlations between the vaiables we used the COREL test. 


\section{RESULTS AND DISCUSSIONS}

\section{Clinical data}

General clinical data such as age, weight, height and body mass index (BMI) of the patients included in our study are presented in Table 1.

TABLE 1. Clinical data of the subjects included in the study

\begin{tabular}{|l|c|c|c|c|}
\hline & $\begin{array}{c}\text { Age } \\
\text { (years) }\end{array}$ & $\begin{array}{c}\text { Weight } \\
\text { (kg) }\end{array}$ & $\begin{array}{c}\text { Height } \\
\text { (cm) }\end{array}$ & $\begin{array}{c}\text { BMI } \\
\text { (kg/m) }\end{array}$ \\
\hline Group 1 -controls \\
\hline mean & 37.18 & 73.41 & 172.82 & 21.24 \\
\hline SD & 9.08 & 4.87 & 5.28 & 1.21 \\
\hline Group 2 CHB \\
\hline mean & 31.50 & 74.64 & 174.71 & 21.36 \\
\hline SD & 9.68 & 5.09 & 4.63 & 1.28 \\
\hline Group 3 CHC \\
\hline mean & 44.91 & 69.75 & 170.45 & 20.45 \\
\hline SD & 14.88 & 8.63 & 3.91 & 2.43 \\
\hline Group 4 ACH & & & \\
\hline mean & 41.79 & 74.47 & 171.74 & 21.65 \\
\hline SD & 6.72 & 7.37 & 5.58 & 1.66 \\
\hline
\end{tabular}

\section{Salivary levels of total protein, $\lg G$ and $\lg A$}

Salivary total protein levels are significantly higher in patients with chronic viral hepatitis compared to the healthy subjects $(2.97 \pm 0.59$ $\mathrm{g} / \mathrm{l}$ for group 2 and $2.82 \pm 0.64 \mathrm{~g} / \mathrm{l}$ for group 3 versus $1.37 \pm 0.40 \mathrm{~g} / \mathrm{l}$ in controls). Although total protein showed increased salivary levels in patients with chronic hepatitis of alcoholic etiology, the results were not statistically significant (Fig. 1).

The predominant immunoglobulin in saliva is IgAs (6). Our results showed significantly increased salivary levels of IgA in patients with chronic hepatitis versus controls: $27 \pm 7.63 \mathrm{mg}$ / $\mathrm{dl}$ in the CHB group, and $37.87 \pm 19.74 \mathrm{mg} / \mathrm{dl}$ in the $\mathrm{CHC}$ group compared to $12.10 \pm 4.70 \mathrm{mg} / \mathrm{dl}$ in normal, healthy subjects (Fig. 1).

Total saliva has a complex composition, also containing gingival crevicular fluid and constituents of the dental plaque. Apart from IgA, IgM and IgG can also be found in total saliva. The salivary presence of these antibodies with specificity for infections with VHB and VHC allows the diagnostics of these viral infections (6).

Compared to the controls, the subjects included in the third group had higher salivary levels of IgG $(2.38 \pm 0.39 \mathrm{mg} / \mathrm{dl}$, respectively $2.93 \pm$ $0.82 \mathrm{mg} / \mathrm{dl}, \mathrm{p}=0.01$ ). The second group of patients also showed increased salivary levels of IgG versus the healthy subjects $(2.65 \pm 0.67 \mathrm{mg} /$ $\mathrm{dl})$, but the results were not statistically significant $(p>0.05)$.

Patients with chronic alcoholic hepatitis had significantly higher concentrations of both IgA and IgG compared to controls with mean salivary levels of $22.38 \pm 7.09 \mathrm{mg} / \mathrm{dl}$ and $3.03 \pm 0.64$ $\mathrm{mg} / \mathrm{dl}$, respectively (Fig. 1). Similar results regarding IgA levels have been found by Gonzalez-Quintela $A$ et al. However, their study did not reveal such data for IgG salivary concentrations in patients with chronic alcoholic hepatitis (7). Our findings could be explained by the effects that chronic alcohol consumption has on salivary glands and/or on the oral mucosa, with an increased capillary permeability and facilitation of plasmatic immunoglobulin transportation into the saliva.

The IgA/IgG ratio was also significantly higher in chronic hepatitis patients compared to the controls $(4.90 \pm 2.20$ for controls, $10.69 \pm 3.51$

Salivary levels of TP, IgG, IgA and IgA/lgG

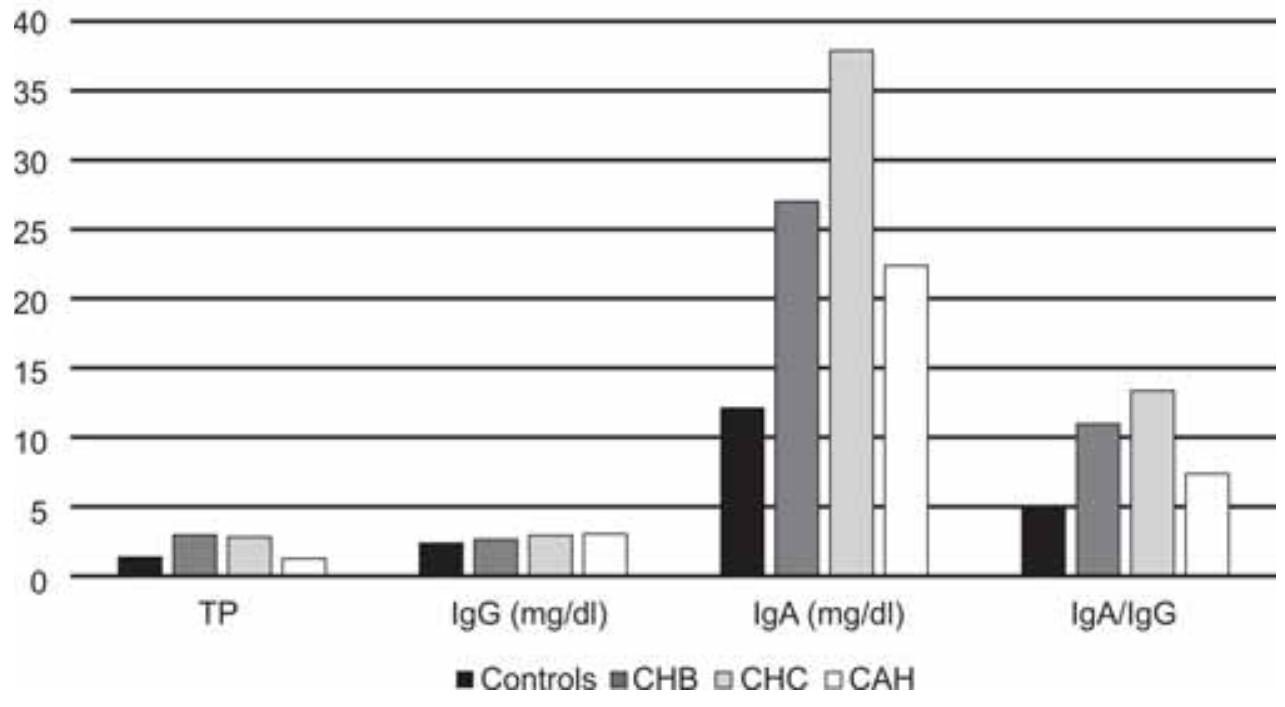

FIGURE 1. Salivary levels of proteins for all subjects 
for $\mathrm{CHB}, 13.37 \pm 6.89$ for $\mathrm{CHC}$ and $7.38 \pm 2.49$ for $\mathrm{CAH})$, because although both immunoglobulins had increased concentrations, the difference was more important for IgA (Fig. 1).

\section{Salivary levels of AST and ALT}

Both aminotransferases have a normal serum concentration of 8-40 $\mathrm{U} / \mathrm{I}$ and their increased levels for more than 6 months allow the diagnosis of a chronic disorder. Most commonly, their increase suggests liver impairment because of the high quantities of the enzymes in the hepatocytes. However, in some cases increased levels of aminotransferases are due to medicines used to treat tuberculosis, celiac disease, thyroid ailments, muscular or myocardial afflictions, mononucleosis and different types of acute viral fever or after alcohol consumption $(8,9,10)$. While ALT is considered to have an exclusive hepatic origin, being found in the hepatocytes, AST comes mostly from the liver, but from muscles and myocardia as well. It has been observed that in most disorders with increased levels of transaminases, ALT has higher concentrations compared to AST, excepting liver impairment of alcoholic etiology, where AST presents higher levels, sometimes even 2-3 times more than ALT (8).

Our study exhibited increased salivary levels for both AST and ALT in all patients with chronic hepatitis compared to the healthy subjects, a high statistical significant being found for all three groups $(p<0.01)$. The results for the control group revealed mean salivary AST concentrations of $24.14 \pm 8.39 \mathrm{U} / \mathrm{l}$ for the control group, $69.57 \pm 36.74 \mathrm{U} / \mathrm{l}$ for the $\mathrm{CHB}$ group, $67.32 \pm$ $24.58 \mathrm{U} / \mathrm{I}$ for the $\mathrm{CHC}$ patients and $74.37 \pm 47.38$ $\mathrm{U} / \mathrm{I}$ for the $\mathrm{ACH}$ patients, respectively (Fig. 2).

At the same time, ALT salivary concentrations were $11.86 \pm 3.17 \mathrm{U} / \mathrm{l}$ for the controls, $98.64 \pm 55.67 \mathrm{U} / \mathrm{l}$ for the CHB patients, $100.00 \pm$ $50.90 \mathrm{U} / \mathrm{I}$ in the $\mathrm{CHC}$ group and $80.42 \pm 45.53$ $\mathrm{U} / \mathrm{I}$ in $\mathrm{CAH}$ patients (Fig. 3 ).

AST and ALT increased plasmatic levels are considered valuable biomarkers for liver impairment and cellular necrosis (11). The significantly increased salivary concentrations for these enzymes in patients with chronic hepatitis promote the use of salivary AST and ALT levels as potential screening and monitoring tests for liver disorders. On the other hand, there are studies that displayed similar results for different diseases such as diabetes mellitus (12) or periodontal disease (13).

AST/ALT plasmatic ratio is also used to diagnose acute or chronic liver disease, in most cases having a value equal or smaller than 1 . This rate is particularly seen in patients with chronic viral hepatitis, while a ratio bigger than 2 is more commonly met in chronic alcoholic hepa-

\section{Salivary AST levels}

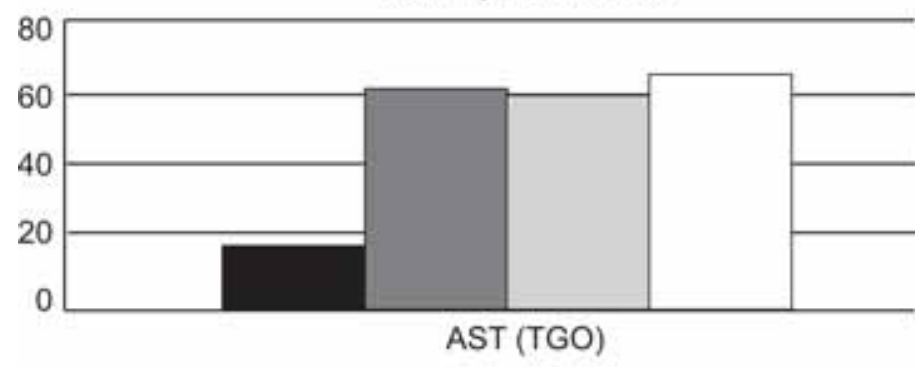

Controls $\mathrm{CCHB} \square \mathrm{CHC} \square \mathrm{CAH}$

Salivary ALT levels

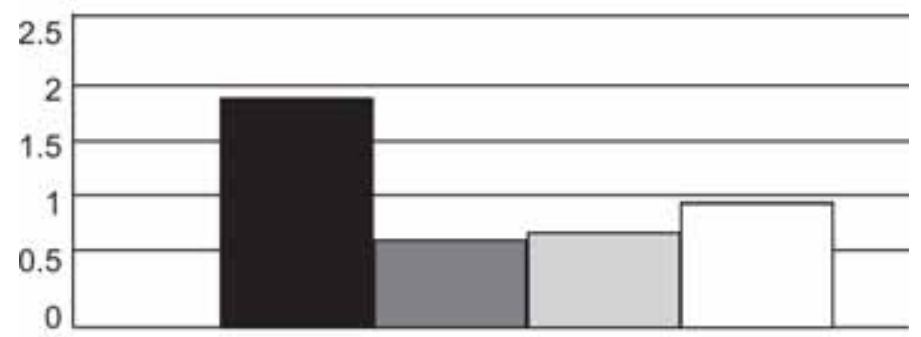

AST/ALT

Controls $\square \mathrm{CHB} \square \mathrm{CHC} \square \mathrm{CAH}$
FIGURE 3. Salivary ALT levels for all participants to the study 


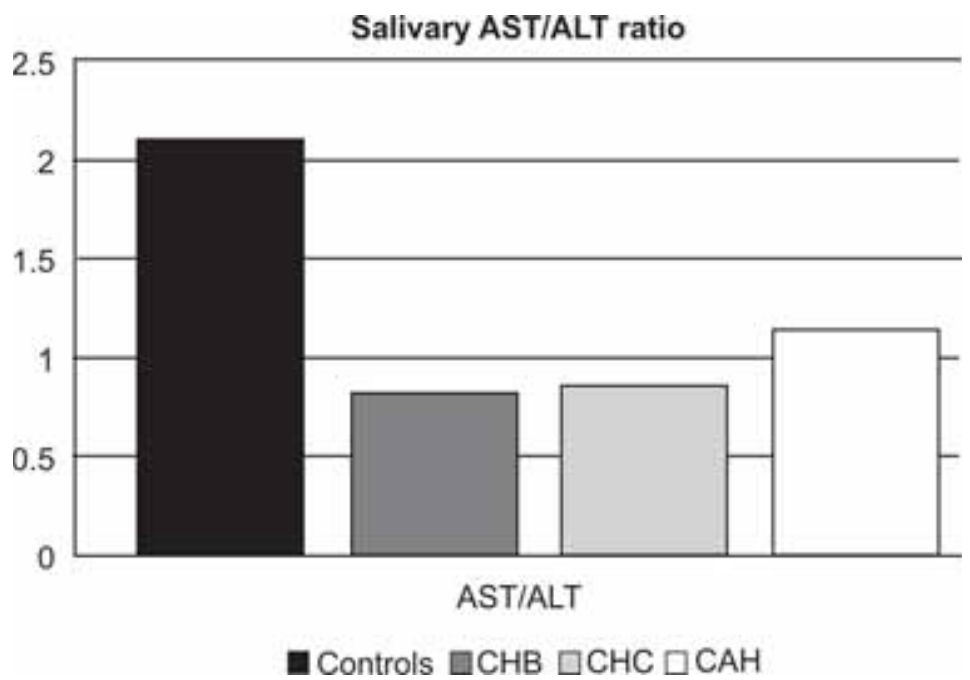

FIGURE 4. Salivary AST/ALT ratio in patients with chronic hepatitis compared to the control group titis. Sorbi D et al. have found that patients with non-alcoholic steatohepatitis have a AST/ALT ratio of less than 1 (mean of 0.9 ), while in patients with $\mathrm{CAH}$ the ratio is $>2$ (mean of 2.6) (14). This is explained by the more important increase in AST concentration when the liver impairment is caused by alcohol consumption. Therefore, in cases of hepatitis where salivary leveles of aminotransferases are increased, the AST/ALT ratio can be used to assess the etiology.

Our study showed that healthy subjects had a AST/ALT ratio of $2.12 \pm 0.70$, while in patients with viral chronic hepatitis the ratio was under 1: $0.81 \pm 0.43$ for group 2 and $0.86 \pm 0.56$ for group 3. Group 4 had a AST/ALT ratio of $1.15 \pm$ 0.75 . Thus, all patients with hepatitis had significantly lower ratio compared to the controls $(p<0.01)$ (Fig. 4).

\section{CONCLUSIONS}

The results of the present study reflect significant changes in salivary levels of the parameters we determined between patients with chronic hepatitis and healthy subjects, thus promoting the use of this remarkable fluid to monitor and evaluate disease activity and etiology. However, further research is needed in order to use saliva as an exclusive tool for the diagnosis of these pathologies.

\section{Acknowledgements}

All authors contributed equally to the present work.
Conflict of interest: none declared Financial support: none declared

\section{REFERENCES}

1. Martí-Álamo S., Mancheño-Franch A., Marzal-Gamarra C. et al. Saliva as a diagnostic fluid. Literature review. J. Clin. Exp. Dent. 2012; 4(4): e237-e243.

2. Ott J.J., Stevens G.A., Groeger J. et al. Global epidemiology of hepatitis $B$ virus infection: new estimates of age-specific HBsAg seroprevalence and endemicity. Vaccine, 2012; 30(12): 2212-2219.

3. Hammer G.D., McPhee S.J. Pathophysiology of Disease 7th Edition. 2014: p. 544-553.

4. Barrio E., Tome S., Rodriguez I. et al. Liver disease in heavy drinkers with and without alcohol withdrawal syndrome. 156
Alcohol. Clin. Exp. Res. 2004; 28(1): 131-136.

5. Tengan F.M., Levy-Neto M., Miziara I.D. et al. Extrahepatic manifestations of chronic hepatitis $C$ infection: a consecutive study in Brazilian patients. Braz. J. Infect. Dis. 2017; 21(2): 203-204.

6. Corstjens P.L., Abrams W.R., Malamud D. Detecting viruses by using salivary diagnostics.J. Am. Dent. Assoc. 2012; 143: 12S-18S.

7. Gonzalez-Quintela A., Alende R., Gude F. et al. Serum levels of immunoglobulins ( $\lg G, \lg A, \lg M)$ in a general adult population and their relationship with alcohol consumption, smoking and common metabolic abnormalities. Clin. Exp. Immunol. 2008; 151(1): 42-50.

8. Oh R.C., Hustead T.R. Causes and evaluation of mildly elevated liver transaminase levels. Am. Fam. Physician. 2011; 84(9): 1003-1008.

9. Castillo N.E., Vanga R.R., Theethira T.G. et al. Prevalence of abnormal liver function tests in celiac disease and the effect of a gluten-free diet in the US population. Am. J.Gastroenterol. 2015; 110(8): 1216.

10. Pavletic A.J., Wright M.E. Exerciseinduced elevation of liver enzymes in a healthy female research volunteer.

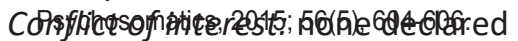
Financial support: none declared 
11. Giboney P.T. Mildly elevated liver transaminase levels in the asymptomatic patient. Am. Fam. Physician. 2005; 71(6): 1105-1110.

12. Dabra S., China K., Kaushik A. Salivary enzymes as diagnostic markers for detection of gingival/periodontal disease and their correlation with the severity of the disease. J. Indian Soc. Periodontol. 2012; 16(3): 358-364.

13. Luke R., Khan S.N., Iqbal P. et al.

Estimation of Specific Salivary Enzymatic Biomarkers in Individuals with Gingivitis and Chronic Periodontitis: A Clinical and Biochemical Study. J. Int. Oral Health. 2015; 7(9): 54-57.
14. Sorbi D., Boynton J., Lindor K.D. The ratio of aspartate aminotransferase to alanine aminotransferase: Potential value in differentiating nonalcoholic steatohepatitis from alcoholic liver disease. Am. J. Gastroenterol. 1999; 94(4): 1018-1022. 